\title{
A NOVEL FOAM COATING APPROACH TO PRODUCE ABRASIVE STRUCTURES ON TEXTILES
}

\author{
Eija Kenttä1, ${ }^{1,}$ Vinay Kumar ${ }^{1}$, Petter Andersson ${ }^{2}$, Ulla Forsström ${ }^{1}$ \\ 1 Biomaterial Processing and Products, VTT Technical Research Centre of Finland Ltd, P.O. Box 1000, FI-02044 VTT, Finland \\ 2 Mirka Ltd., FI-66850 Jepua, Finland \\ *Corresponding author. E-mail: eija.kentta@vtt.fi
}

\begin{abstract}
:
Abrasive materials are classified as paper, nonwoven, or plastic-based multilayer structures, which are used for different kinds of surface finishing. Currently, the production of abrasive structures on textiles is carried out by spraying a slurry of binder and abrasive particles, e.g., $\mathrm{Al}_{2} \mathrm{O}_{3}$ or $\mathrm{SiC}$, with subsequent drying and curing of the binder. The drawback of this production method is the poor runnability of the spraying process. Even small variations in the process parameters may lead to an uneven coating. Therefore, a novel coating approach was developed to produce abrasive structures with foam coating on textile substrates. The foam coating method, which is commonly used in the textile industry, has the potential to produce an even coating layer. The runnability and reliability of the foam coating process are good even with high solids. From a workplace safety perspective, another advantage of foam coating is that there are no airborne particles during the coating process. A polyamide woven cloth was foam coated with an aqueous slurry containing abrasive grains (SiC), a water-based UV-curable acrylate binder, and cellulose nanocrystals (CNCs) to adjust the slurry rheology. Stable abrasive-binder foams were generated from the slurries even at high solids of $50 \%$ using an anionic foaming agent. The cloth was foam coated and dried, and the resin was cured with a LED-UV lamp on a pilot scale. It was observed that without the addition of CNC the foam did not stay on the surface of the cloth after coating. CNC acts as a rheology modifier and co-binder, which prevent the foam from penetrating deeper into the pores of the cloth. CNC also acted as a dispersing agent: the slurry was effectively stabilized by the CNC to prevent sedimentation of the abrasive grains. An organic solvent-free composition was introduced by combining CNC with a water-based UV-resin.
\end{abstract}

\section{Keywords:}

Foam, foam coating, abrasive, cellulose nanocrystals

\section{Introduction}

The foam coating process is an established technology for coating or finishing woven and nonwoven fabric webs. The main advantages of this process are (1) reduction of water, (2) reduction of chemical consumption, and (3) savings in energy costs [1]. In this process, the coating material, water, and a foaming agent are mixed with pressurized air using a foam generator. The mixture of foam coating material is transferred to the coating unit and applied on the substrate. After foam application, the air bubbles collapse mainly because of liquid absorption. Uniform spreading and collapsing of the foam require that the substrate should absorb the coating solution. The foam normally contains around $90 \%$ of air. Therefore, to achieve the desired coat weight, ten times or more thick foam layer is spread on the moving web than with dispersion coating. This makes it possible to apply a small amount of material evenly over the substrate. High viscosity gel-like coating materials, such as cellulose nanofiber suspensions at low consistencies (e.g., $2 \%$ ), can be foam coated. Based on the experimental work in pilot scale, the key requirement of foam coating is that the foamed material can be pumped to the applicator and a stable enough foam is applied on the substrate [2, 3].
In a rotor-stator mixer, kinetic energy is supplied to mix a gas phase and a liquid phase under foaming conditions. The structure of the foam is characterized by the volumetric ratio of gas and liquid in the foam and the bubble size distribution [4]. The stability of the aqueous foams is influenced by the bubble size distribution and the gas-liquid fraction. Therefore, the determination of the bubble size and its distribution after foam generation is used to characterize foam properties and the stability of those properties [5-8]. Foams are principally unstable and the distribution of gas and liquid phase in the foam is changing with time. Three mechanisms destabilize foam: drainage, coalescence, and coarsening. Drainage is the liquid flow from the foam leading to drier foams. If the film between gas bubbles is unstable, it can break, resulting in the merging of the bubbles. This mechanism is called coalescence. The third mechanism of destabilization is coarsening: gas diffuses between bubbles of different radii due to the difference in the Laplace pressure. The gas is transferred from smaller to bigger bubbles, leading to the disappearance of the smaller bubbles. Coalescence and coarsening lead to an increase of the average bubble size with time [6, 9]. 
Aqueous foam stability can be enhanced with the presence of solid particles, polymers, proteins, and surfactant molecules. At the air/water interfaces, the foam stabilizer has to get rapidly to the gas/liquid interface to produce foam. The stabilizer has also to create a surface that is stable against coalescence by making it sufficiently viscoelastic. In foam liquid channels, the stabilizers can form self-assembled and aggregated structures and increase the viscosity of the liquid phase, leading to a slow down or suppression of drainage [9]. Solid particles with surfactants can be the effective stabilizers of aqueous foams. The particle size, concentration, hydrophilicity, and intermediate wettability are identified as the main factors for foam stabilization [9-11].

Abrasive materials can be categorized into paper, nonwoven, or plastic-based multilayer structures used for different kinds of surface finishing. Sanding and polishing are essential phases in premium surface finishing, such as automotive production, where small painting defects are removed by sanding. Wooden surfaces of the furniture are sanded before varnishing or painting, and surfaces with multiple varnishes or paint layers are sanded before adding a new layer to obtain the required surface quality. In abrasive multilayer structures, radiationcurable synthetic polymer resins are binding and stabilizing the abrasive particles, which are inorganic materials, e.g., $\mathrm{Al}_{2} \mathrm{O}_{3}$, $\mathrm{SiC}$, of various sizes, $1 \mu \mathrm{m}-2,000 \mu \mathrm{m}$, varying according to use. Currently, the production of abrasive layers on a cloth is carried out by spraying a slurry of binder and abrasive particles onto the substrate with subsequent drying and curing of the binder. The drawback of this production method is the poor runnability of the spraying process that results in an uneven coating already with small variations in production parameters. When hard particles like coating pigments or abrasives are coated using the spray coating process, the lifetime of the nozzles is quite short due to wear, and the spray nozzles need regular cleaning [12]. With the foam coating technique wearing is avoided as the solid abrasive particles are transferred and applied on the substrate through a slot applicator within the foam air bubbles instead of several spray nozzles. In addition, when the stable foam is obtained, foam coating conditions are more stable than by spraying the slurry of binder and particles.

Cellulose nanocrystals (CNCs) produced by sulfuric acid treatment from chemical pulp are needle-shaped crystals, negatively charged, and hydrophilic. The negatively charged sulfate groups provide electrostatic stability to CNCs in polar aqueous suspensions [13, 14]. Nanocelluloses easily form hydrogel structures, i.e., a material composed mainly of water that is contained in a hydrophilic, polymer matrix. The viscosity and moduli of CNC dispersions increase steeply with concentration, and two critical values are observed, namely the overlap and the gelation concentration, which depend strongly on the aspect ratio of the crystals. The thickening effect provided by the presence of nanocellulose in aqueous dispersions is attributed to the entanglement of the cellulosic chains that creates a network $[15,16]$. Various studies of CNC composites have shown that the viscoelastic properties of CNC-polymer nanocomposites strongly depend on the CNC content. Even at low CNC loading, the storage modulus significantly increases compared with the neat polymer matrix [17]. Even within the dilute concentration regime ( $<0.5$ vol- $\%)$, CNC can form gels either by adding a high concentration of electrolyte or a low concentration of non-adsorbing polymer. These properties with other properties of $\mathrm{CNC}$, such as nontoxicity and density, make $\mathrm{CNC}$ interesting for applications in aqueous systems such as thickeners for coatings, drilling, and cement admixtures or as emulsion stabilizers [18-21].

This work aims to create foams from abrasive slurries having high solids content (>10 wt-\%) and to explore non-contact foam coating techniques by applying a thick layer of abrasive material on a porous substrate. CNC is utilized as a co-binder to create a formulation of small abrasive particles with only water-based organic binders for high-end surface finishing applications. The foam coating application offers better possibilities for runnability than spray coating application that enables less waste, more resource-efficient, and safer production, which leads to more sustainable products.

\section{Materials and methods}

\subsection{Materials}

The main component of the foam coating formulation was abrasive particles of silicon carbide, $\mathrm{SiC}$ with a particle size of $9 \mu \mathrm{m}$ (Carborex, Washington Mills). An additive filler of fumed silica, $\mathrm{SiO}_{2}$ nanoparticle dispersion (AERODISP $® \mathrm{~W}$ 1226), was purchased from Evonik. A water-based UV-resin binder (Ucecoat ${ }^{\circledR} 7177$ ) was purchased from Allnex. CNCs, trade name Celluforce $\mathrm{NCC}^{\mathrm{T} M}$, were purchased from Celluforce. A photoinitiator for the UV resin (Esacure KTO 46, IGM Resins B.V.) was also used. Weylchem International $\mathrm{GmbH}$ provided the foaming agent, Weylclean SAS 30 , a secondary alkane sulfonate sodium salt. The substrate used in the foam coating was a polyamide, knitted, and open structure textile, which is used in the production of one current abrasive product, grammage $74 \mathrm{~g} / \mathrm{m}^{2}$ (see Figure 7a). Scanning electron microscope (SEM) images of $\mathrm{SiC}$ abrasive particles and $\mathrm{SiO}_{2}$ nanoparticles were obtained with a Merlin Field Emission (FE)SEM (Carl Zeiss NTS GmbH, Oberkochen, Germany) using secondary electron (SE) detector Figure 1. The electron gun voltage was $2 \mathrm{kV}$ and the probe current was $60 \mathrm{pA}$.

\subsection{Laboratory scale study of abrasive slurries}

The foam coating slurries were developed and explored first on a laboratory scale. The laboratory-scale study was focused on studying the foaming ability of abrasive particles with water-based UV-resin and CNC binder systems at high

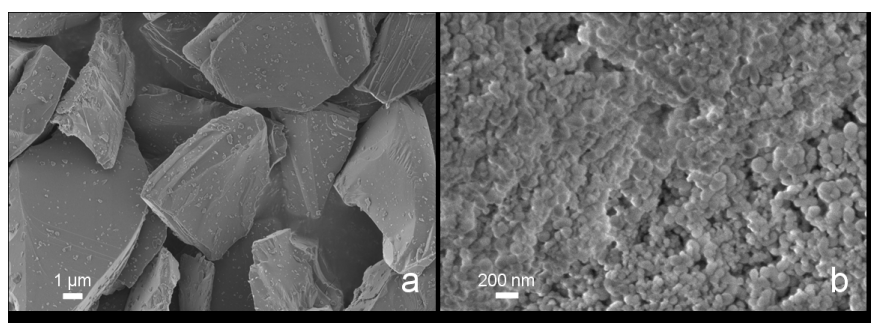

Figure 1. SEM image of $\mathrm{SiC}$ abrasive particles (a) and $\mathrm{SiO}_{2}$ filler nanoparticles (b). SEM, scanning electron microscope. 
Table 1. Abrasive binder formulations.

\begin{tabular}{|c|c|c|c|c|c|c|c|}
\hline Formulation & $\begin{array}{c}\text { SiC dry, } \\
\mathbf{w t} \%\end{array}$ & $\begin{array}{c}\mathbf{S i O}_{2} \text { dry, } \\
\mathbf{w t} \%\end{array}$ & $\begin{array}{c}\text { UV resin } \\
\text { dry, wt\% }\end{array}$ & $\begin{array}{c}\text { CNC dry, } \\
\mathbf{w t} \%\end{array}$ & $\begin{array}{c}\text { Solids } \\
\text { content, } \%\end{array}$ & $\begin{array}{c}\text { Viscosity } \\
\text { at 100 rpm, } \\
\text { mPa.s }\end{array}$ & $\begin{array}{c}\text { Foam } \\
\text { density, g/l }\end{array}$ \\
\hline F1_Lab & 70 & 0 & 30 & 2 & 50 & 3310 & 130 \\
\hline F2_Lab & 70 & 0 & 30 & 3 & 48 & 7450 & 140 \\
\hline F3_Lab & 56 & 14 & 30 & 2 & 50 & 3990 & 100 \\
\hline F4_Lab & 56 & 14 & 30 & 3 & 48 & 7700 & 100 \\
\hline F5_Lab & 56 & 14 & 30 & 5 & 45 & 9800 & 105 \\
\hline
\end{tabular}

CNC, cellulose nanocrystal.

solids content. Thereafter, the foams were applied onto a textile substrate using an Erichsen laboratory coater, and the coating quality obtained was visually evaluated for its abrasive function. Homogenous slurries containing the abrasive, filler, and binder were prepared in tap water by mixing with a laboratory dissolver Dispermat ${ }^{\circledR} \mathrm{TU}$ at 2,000 rpm for $30 \mathrm{~min}$. Before addition to the slurry, the CNC powder was dispersed into deionized water by stirring at 3,000 rpm for $3 \mathrm{~h}$ to prepare a $10 \mathrm{wt}-\%$ gel. The addition level of CNC to the formulations was as dry wt $\%$ of the total dry amount of abrasive, filler, and binder. The foaming agent was added at $0.3 \mathrm{wt} \%$ of the total dry matter, and the UV-photoinitiator was added as $5 \mathrm{wt} \%$ of the dry UV-resin amount. The five formulations with varying levels of CNC are listed in Table 1.

\subsection{Abrasive slurry characterization}

The viscosity of abrasive slurries was measured with an Anton Paar MCR 301 rheometer using cone-plate geometry. The slurry viscosities at $100 \mathrm{rpm}$ are shown in Table 1. The stabilizing effect of $\mathrm{CNC}$ on $\mathrm{SiC}$-water slurry stability was studied with a turbidity measurement using a TurbiScan Lab (Formulation SA; L'Union, France) device. The backscattering value of SiC-water slurry as such and with two parts of CNC was recorded every $4 \mathrm{~s}$ for $5 \mathrm{~min}$ after slurry preparation. The backscattering values were ratioed against the starting point to clarify the comparison between the two compositions. The SiCslurries had a solids content of $10 \mathrm{wt}-\%$ and $1 \mathrm{wt}-\%$ in turbidity measurement.

\subsection{Abrasive foaming and foam characterization}

Abrasive foams were produced on a laboratory scale using a Kenwood Chef mixer for 10 min at maximum speed. Foam half-life time was estimated by following visually the separation of the water from the freshly prepared foam in a measuring vessel. Foam density was measured by weighing after foaming. Table 1 shows the foam densities. Bubble size determination based on optical imaging was targeted to use, according to the method developed for wet foams [22, 23]. The foam sample was collected by dipping a cuvette into the freshly generated foam. Unfortunately, because of the highly non-transparent abrasive foams, the optical imaging was not able to detect the details of the bubbles in foams.
A multiple light scattering analysis with an optical analyzer Turbiscan has proven to a versatile tool to characterize emulsions, suspensions, and foams without dilution in a wide range of particle volume fractions (0-90\%) and particle size $(0.1-1,000 \mu \mathrm{m})$ for formulation and quality control purposes [24]. Foam bubble size evolution can be extracted from the average backscattering of the foam [25, 26]. Since, in this study, foams were produced at high concentrations of abrasive particles and binders, it is assumed that the changes in the backscattering value of these abrasive foams indicate the stability of the whole foam structure, and not merely the growth of bubble size. An abrasive foam stability test with turbidity measurement was conducted by recording the backscattering value of the foam every $2 \mathrm{~s}$ for a total of $20 \mathrm{~min}$ after foam generation. Foam turbidity was measured from the abrasive formulations chosen to pilot trials and foams were produced with a small rotor-stator PICO-MIX foam generator (Hansa Industrie-Mixer GmbH\&Co KG) using mixing speed 1,200 rpm, pump speed of $6 \mathrm{l} / \mathrm{h}$, and target density of $100 \mathrm{~g} / \mathrm{l}$. The stability of water-surfactant Weylclean SAS 30 (0.3 wt-\%) foam was measured similarly, as a reference.

\subsection{Laboratory foam coating}

Abrasive foams were applied on the textile substrate with the Erichsen laboratory coater and dried in the oven for $5 \mathrm{~min}$ at $105^{\circ} \mathrm{C}$; after this, the resin was cured by a LED UV-lamp at a wavelength of $395 \mathrm{~nm}$. The coating quality was evaluated visually and abrasive particles stayed best on the cloth substrate surface at the highest slurry solids content of $50 \mathrm{wt}-\%$ (F1_Lab and F3_Lab). In addition, the use of silica filler in the formulation (F3_Lab, F4_Lab, and F5_Lab) seemed to further diminish abrasive migration into cloth pores.

Laboratory foam coatings of abrasives with silica filler, formulations F3_Lab, F4_Lab, and F5_Lab, were chosen for a sanding test. A reference sample of the existing abrasive product (Abralon 3000) was included in the test. Abrasive surface gloss was measured before sanding and after $1 \mathrm{~min}$ of sanding on a clear coat. It is emphasized that the gloss values of foam coated abrasive layers are not similar to the reference abrasive product because of differences in abrasive layer structure and abrasive formulation. However, the sanding test is capable to show the gloss change due to the sanding: a 
minor gloss increase indicates minimal wearing of the abrasive layer. Sanding results indicated that foam coated abrasive layers had the same level of wearing as the reference sample (see Table 2). The gloss increase was similar or even lower in foam coated abrasives than in the reference sample.

\subsection{Foam generation and foam coating pilot trials}

Based on the foaming study and laboratory-scale foam coating results, the formulations F1_Lab and F3_Lab were picked for pilot-scale coating. These two formulations had the highest solids content of $50 \%$, which affected the best abrasive particle attachment on the substrate surface. The performance of silica filler as further diminishing the abrasive layer penetration into cloth pores was also verified in the pilot-scale trial. F3_Lab had a small gloss increase, indicating minimal wearing of the abrasive layer. Pilot formulations were prepared by mixing the components at speeds of 2,000 rpm. After adding the foaming agent, a short gentle mixing was performed, and the slurry was transferred to a foam generator. The foam was generated with a Top-Mix 60 rotor-stator foam generator (Hansa IndustrieMixer $\mathrm{GmbH} \&$ Co. $\mathrm{KG}$ ) operating at pressure $\sim 3$ bar, mixing speed $500 \mathrm{rpm}$, pump speed $10 \mathrm{l} / \mathrm{h}$, and target density $100 \mathrm{~g} / \mathrm{l}$.

The generated foam was applied with a Magnojet slot-die applicator (Zimmer Maschinenbau $\mathrm{GmbH}$; Austria) onto a moving textile web using VTT's surface treatment concept pilot line, as shown in Figure 2. Formulations of foam coating trials, slurry viscosities, and foam densities are listed in Table 3 . The coating speed was $15 \mathrm{~m} / \mathrm{min}$. Three IR and five airfoil dryers were used for drying, and a LED UV-curing unit was used with a UV-lamp (wavelength $395 \mathrm{~nm}$ ) operating at 100\% power and $3 \mathrm{~cm}$ distance from the web.

\subsection{Characterization of pilot foam coated samples}

Grammage of the textile substrate and foam coated samples were determined by weighing a known sample size, and coat weight was obtained as a difference of grammages of the substrate and their coated counterparts. The thickness of the uncoated substrate and foam coated samples was determined using an L\&W Micrometer, and coating thickness was obtained as a difference of thicknesses of the substrate and its coated counterpart. SEM images of abrasive coated surfaces were obtained with a Hitachi TM4000Plus SEM.

\section{Results and discussion}

\subsection{CNC as a co-binder in abrasive slurries}

Abrasive-binder slurries with $2-5$ wt\% of CNC had viscosity in a suitable range for foam generation. Comparison of the viscosity curves of abrasive slurries was done between slurries F3_Lab, F4_Lab, and F5_Lab, which had the same abrasive/ filler composition of $70 \mathrm{SiC} / 30 \mathrm{SiO}_{2}$, and $\mathrm{CNC}$ proportion was varied. Results show that $\mathrm{CNC}$ addition into UV-resin-abrasive mixture made the abrasive slurries shear-thinning having steady viscosity decrease with an increase in shear rate, and the slurry viscosity was higher when CNC proportion was

Table 2. Sanding test of laboratory foam coated abrasives on textile.

\begin{tabular}{|c|c|c|c|}
\hline Formulation & $\begin{array}{c}\text { Gloss before sanding, gloss } \\
\text { units }\end{array}$ & Gloss after sanding, gloss units & Gloss increase, gloss units \\
\hline F3_Lab & 51 & 62 & 7 \\
\hline F4_Lab & 51 & 65 & 62 \\
\hline F5_Lab & 59 & 22 & 6 \\
\hline
\end{tabular}

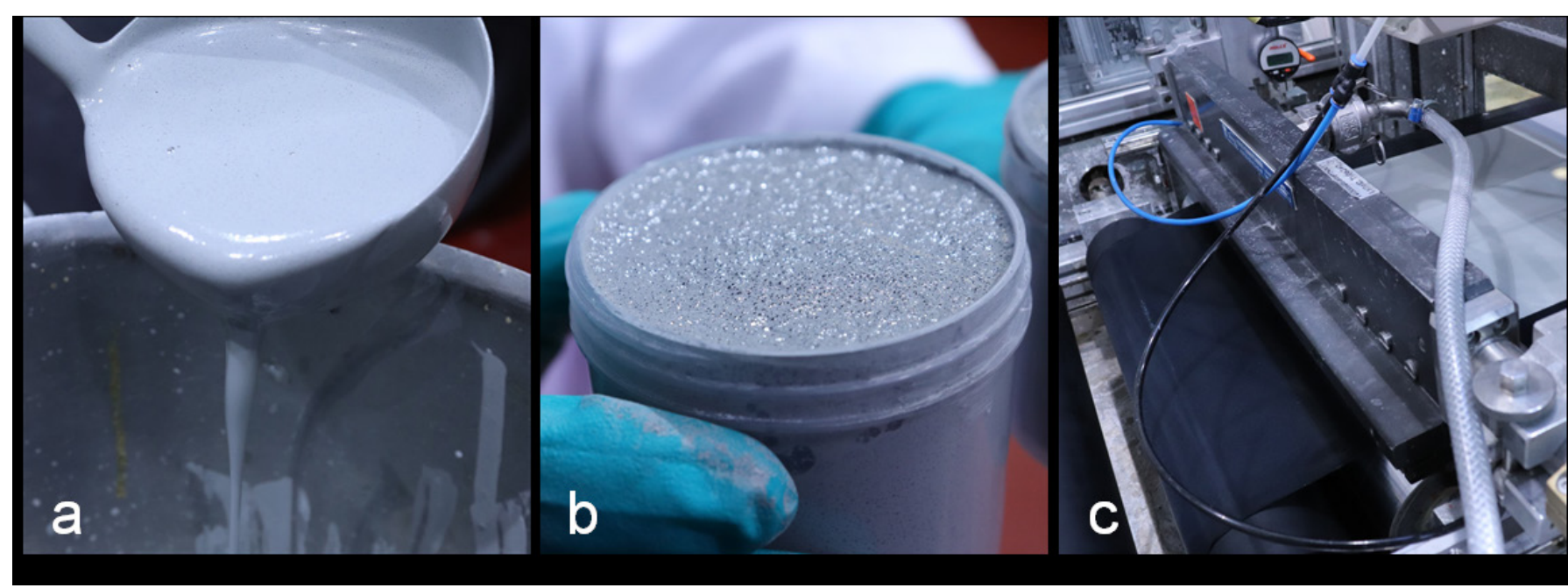

Figure 2. Abrasive slurry (a), slurry foamed (b), and foam application in the pilot trial (c). 
Table 3. Abrasive formulations, pilot trial.

\begin{tabular}{|c|c|c|c|c|c|c|c|}
\hline Formulation & $\begin{array}{c}\text { SiC dry, } \\
\text { wt\% }\end{array}$ & $\begin{array}{c}\mathbf{S i O}_{2} \text { dry, } \\
\text { wt\% }\end{array}$ & $\begin{array}{c}\text { UV resin } \\
\text { dry, wt\% }\end{array}$ & $\begin{array}{c}\text { CNC dry, } \\
\text { wt\% }\end{array}$ & $\begin{array}{c}\text { Solids } \\
\text { content, } \%\end{array}$ & $\begin{array}{c}\text { Viscosity } \\
\text { at 100 rpm, } \\
\text { mPa.s }\end{array}$ & $\begin{array}{c}\text { Foam } \\
\text { density, g/l }\end{array}$ \\
\hline F1_Pilot & 70 & 0 & 30 & 2 & 50 & 4030 & 140 \\
\hline F3_Pilot & 56 & 14 & 30 & 2 & 50 & 6570 & 110 \\
\hline
\end{tabular}

CNC, cellulose nanocrystal.

higher (see Figure 3). Slurries of the $70 \mathrm{SiC} / 30 \mathrm{SiO}_{2}$ mixture with UV-resin and CNC (F3_Lab-F5_Lab) had a somewhat higher viscosity than $\mathrm{SiC}$ abrasive UV-resin slurry without $\mathrm{SiO}_{2}$ at CNC concentrations 2 wt-\% and 3 wt-\% (F1_Lab-F2_Lab), as values in Table 1 show.

CNC performed not only as a rheology modifier but also improved the stability of dispersed abrasives. The stabilizing effect of CNC was verified from SiC-slurries by the turbidity measurement. The abrasive slurry with two parts of CNC showed very stable behavior at $10 \mathrm{wt}-\%$ solids and had better stability also at 1 wt- $\%$ solid compared with abrasive slurry without CNC (see Figure 4).

\subsection{Abrasive foam stability}

Smooth foams were obtained from abrasive slurries using an anionic foaming agent. Foams were stable, having foam half-life time of well over $10 \mathrm{~min}$. The combination of SiC particles with $\mathrm{SiO}_{2}$ nanoparticles produced even smoother foams. The foam stability characterization with the turbidity measurement indicated that abrasive foam structures are very stable. The backscattering value of abrasive foam was almost constant over the measurement period of 20 min after the foam generation. Reference water-surfactant foam is less stable than abrasive foam, as the backscattering value of the plain water-surfactant foam reference was steadily decreasing during the $20 \mathrm{~min}$ after foam generation (see Figure 5). In the abrasive foams, it looks obvious that both solid $\mathrm{SiC}$ abrasive particles and co-binder CNC as a gelling agent have improved the foam stability. The foam stabilization with unmodified CNC is discussed in a study of Hu et al. [27] who demonstrated that unmodified CNC particles stabilized methylcellulose aqueous foams, forming weak gels that inhibit bubble coalescence and

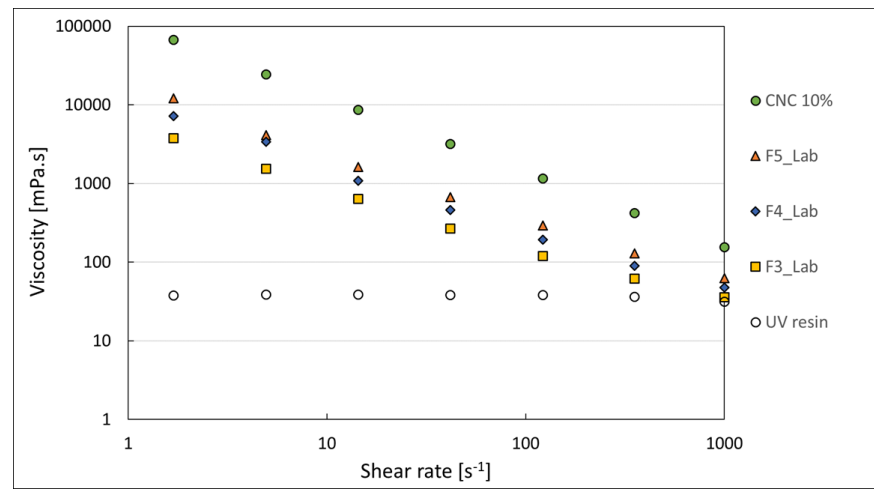

Figure 3. Viscosity against shear rate for UV-resin, formulations F3 Lab, F4_Lab, F5_Lab, and CNC. CNC, cellulose nanocrystal. slow foam drainage. The high concentration of the particles in the abrasive suspension and the resulting yield stress can slow down the drainage, thus leading to a stable foam. As described in a review of foam stability and aging, solid particles with attractive interactions can form aggregated structures, which can be blocked inside the foam liquid channels and increase the viscosity of the liquid phase, leading to a slow down or cessation of drainage [9].

\subsection{Pilot foam coating of abrasives}

In the pilot trials, the target density was set to $100 \mathrm{~g} / \mathrm{l}$, i.e., $90 \%$ of foam is air, and the resultant foam density was varying from $110 \mathrm{~g} / \mathrm{l}$ to $140 \mathrm{~g} / \mathrm{l}$. The foam generation of the slurry at $50 \%$ solids was working as a continuous process. In the formulation F1_Pilot, the retention of abrasive particles on the substrate surface was not good enough, as there seemed to be partial migration deeper into the cloth pores. The second foam coating

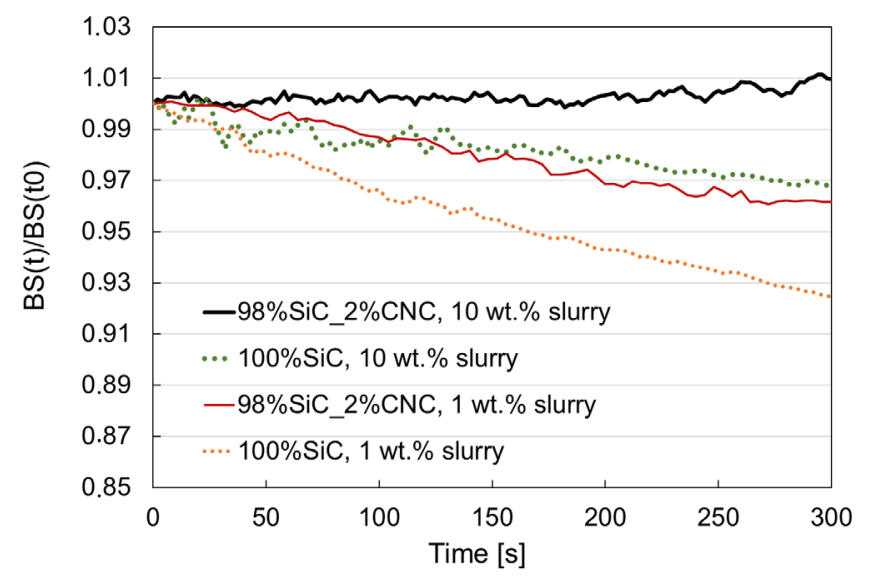

Figure 4. Relative backscattering of abrasive-CNC and abrasive slurries after slurry preparation. CNC, cellulose nanocrystal.

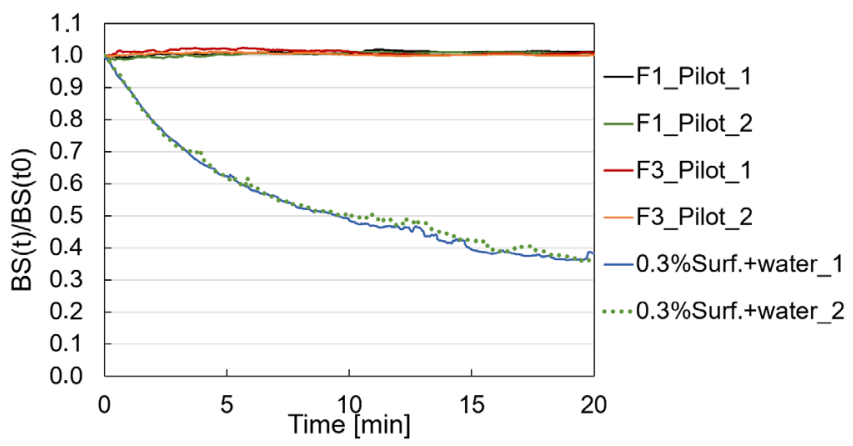

Figure 5. Relative backscattering of abrasive-surfactant and watersurfactant foams after foam generation. 


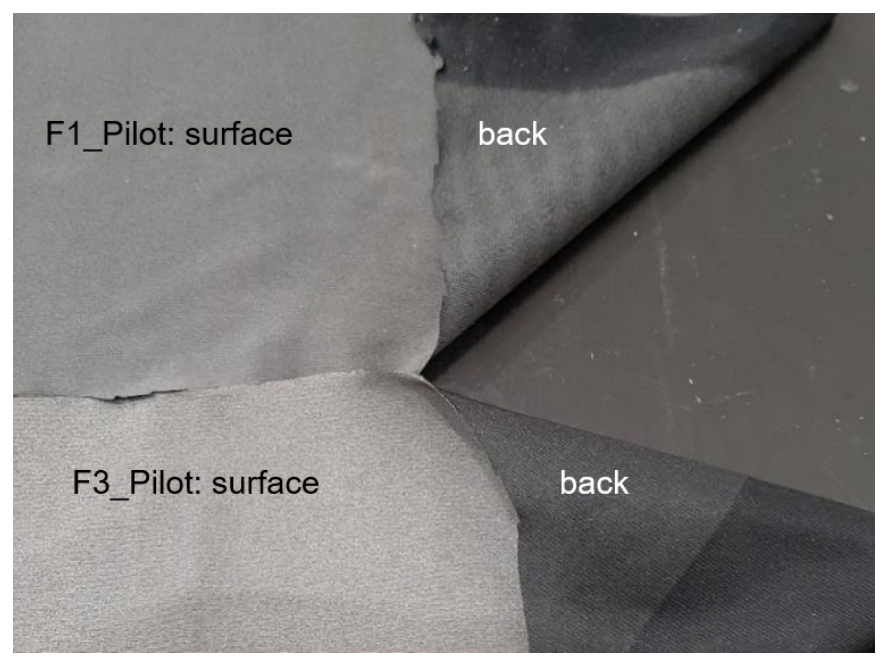

Figure 6. Pilot foam coated cloth with the formulation without filler, F1_Pilot, and with filler, F3_Pilot.

Table 4. Coat weight and thickness results from pilot foam coating trial

\begin{tabular}{|c|c|c|}
\hline Formulation & $\begin{array}{c}\text { Coat weight, } \\
\mathbf{g} / \mathbf{m}^{\mathbf{2}}\end{array}$ & $\begin{array}{c}\text { Layer thickness, } \\
\boldsymbol{\mu m}\end{array}$ \\
\hline F1_Pilot & 27 & 22 \\
\hline F3_Pilot & 20 & 30 \\
\hline
\end{tabular}

formulation F3_Pilot having silica filler with SiC abrasives resulted in improved retention of foam on the cloth surface. There is less migration of abrasive particles to the back of the cloth with the combination of abrasive particles and silica filler (see Figure 6).

The coat weight and thickness of the coatings are shown in Table 4. Coat weight and layer thickness values confirm that the formulation F1_Pilot has penetrated partially into cloth pores. A lower layer thickness of $22 \mu \mathrm{m}$ and a higher coat weight of $27 \mathrm{~g} / \mathrm{m}^{2}$ were obtained using the formulation F1_ Pilot compared with the layer thickness of $30 \mu \mathrm{m}$ and the coat weight of $20 \mathrm{~g} / \mathrm{m}^{2}$ obtained using the formulation F3_Pilot with filler. The abrasive particle deposition on the substrate is visible from the SEM images, shown in Figure 7.

Foam coating surface treatment is typically used to apply dilute chemical solutions forming thin coatings. This work showed that the foam coating technique is working well to apply very thick abrasive layers, $>20 \mu \mathrm{m}$ as a dried layer on a porous substrate. Abrasive-binder slurries were foamed at a high solids content of up to $50 \%$ using low foaming agent concentration (0.3 wt- $\%$ of total solids). The high solids abrasive slurries had viscosity ranging from $3,300 \mathrm{mPa} \times \mathrm{s}$ to $6,600 \mathrm{mPa} \times \mathrm{s}$ at $100 \mathrm{rpm}$, and the rotor-stator generator was able to foam the slurries without any problem. Foams were stable in the time scale of the foam coating process, which makes it possible to obtain uniform coating layers. According to the results obtained, foam coating offers a new and promising concept to make abrasives.

CNC performed as a co-binder and dispersing agent and made the abrasive slurries shear thinning. CNC also improved abrasive slurry and foam stability. In the foam coating process, the migration of abrasive particles deeper into the pores of the textile substrate was further reduced by combining the abrasives with silica filler.

Foam coating of abrasives produced an even abrasive layer. The foam coating process has fewer parameters to control than spray coating, which makes the foam coating a good option to produce abrasive layers on the porous textile substrate. However, the new abrasive recipes still need further development to ensure that the performance of the new, demonstrated abrasive structure is fully in line with the current commercial products. Abrasive structures made with foam coating were estimated to be suitable mainly for finessing type sanding.

\section{Conclusions}

Foam coating as an application technique showed promising results to make abrasive layers using water-based complex abrasive-binder formulations on the absorbing, porous cloth substrate. In pilot-scale coating trials, abrasive slurries at high solids of $50 \%$ were foamable, and the generated foams were very stable in the time range of the coating process. Uniform coating surfaces indicated that stable foam coating conditions were achievable and the turbidity measurements supported this conclusion. The foam coating process has fewer parameters to control than in spray coating and from a workplace safety perspective, another advantage of foam coating is that there are no airborne particles during the coating process. CNCs were acting as a dispersing agent and made the abrasive

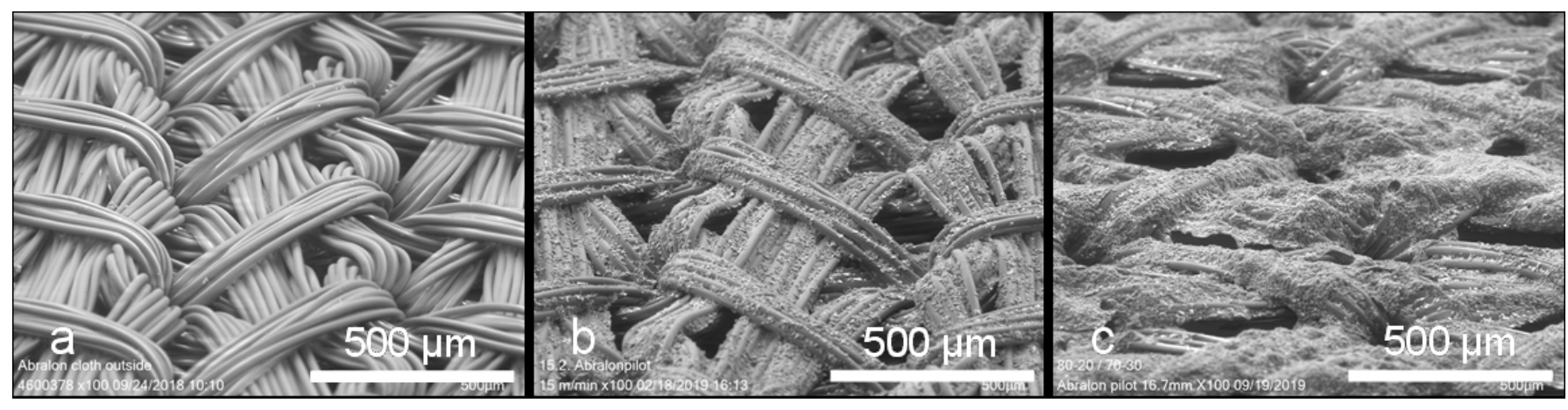

Figure 7. SEM images of plain cloth (a), foam coated cloth with formulation F1_Pilot (b), and F3_Pilot (c). SEM, scanning electron microscope. 
slurries shear thinning and thus had higher viscosity at low shear rates than without CNC. CNC and silica nano pigment were both reducing the migration of abrasive particles deeper into the pores of the textile substrate. Further development of producing abrasive layers with foam coating is still needed to ensure that the performance of the new, demonstrated structure is fully in line with the current commercial abrasive products.

\section{Author contributions}

This manuscript was written through the contributions of all authors. All authors have approved the manuscript.

\section{Acknowledaments}

This work was performed in the NanoTextSurf project.

\section{Funding}

This project has received funding from the European Union's Horizon 2020 research and innovation program under grant agreement No. 760601.

\section{References}

[1] Sen, A. K. (2007). Coated Textiles - Principles and Applications, 2nd edn. CRC Press, Boca Raton, FL, USA, pp. 94-95.

[2] Kinnunen-Raudaskoski, K., Hjelt, T., Kenttä, E., Forsström, $U$. (2014). Thin coatings by foam coating. Tappi Journal, 13(7), 9-19.

[3] Kenttä, E., Koskela, H., Paunonen, S., KinnunenRaudaskoski, K., Hjelt, T. (2016). Functional surfaces produced by foam coating. Tappi Journal, 15(8), 515-521.

[4] Kroezen, A. B. J., Groot Wassink, J. (1986). Foam generation in rotor-stators mixers. JSDC, 102(12), 397-402.

[5] Magrabi, S. A., Dlugogorski, B. Z., Jameson, G. J. (1999). Bubble size distribution and coarsening of aqueous foams. Chemical Engineering Science, 54(18), 4007-4022.

[6] Bisperink, C. G. J., Ronteltap, A. D., Prins, A. (1992). Bubble-size distributions in foams. Advances in Colloid and Interface Science, 38, 13-32.

[7] Jing, J., Sun, J., Zhang, M., Wang, C., Xiong, X., et al. (2017). Preparation and rheological properties of a stable aqueous foam system. RSC Advances, 7(62), 3925839269. doi: 10.1039/C7RA06799B.

[8] Engelsen, C. W., Isarin, J. C. Gooijer, H., Warmoeskerken, M. M. C. G., Groot Wassink, J. (2002). Bubble size distribution of foam. AUTEX Research Journal, 2(1), 1427.

[9] Fameau, A. L., Salonen, A. (2014). Effect of particles and aggregated structures on the foam stability and aging. Comptes Rendus Physique, 15(8-9), 748-760. doi: 10.1016/j.crhy.2014.09.009.

[10] Horozov, T. S. (2008). Foams and foam films stabilized by solid particles. Current Opinion in Colloid and Interface Science, 13(3), 134-140. doi: 10.1016/j.cocis.2007.11.009.
[11]. Hunter, T. N., Pugh, R. P., Franks, G. V., Jameson, G. J. (2008). The role of particles in stabilizing foams and emulsions. Advances in Colloid and Interface Science, 137(2), 57-81. doi: 10.1016/j.cis.2007.07.007.

[12] Husband, J. C., Hiorns, A. G. (2005). The trend towards low impact coating of paper and board. In The 6th European Coating Symposium Proceeding; Bradford, U. K.

[13] de Souza Lima, M. M., Borsali, R. (2004). Rodlike cellulose microcrystals: Structure, properties, and applications. Macromolecular Rapid Communiations, 25(7), 771-787. doi: 10.1002/marc.200300268.

[14] Tayeb, A. H., Amini, E., Ghasemi, S., Tajvidi, M. (2018). Cellulose nanomaterials-binding properties and applications: A review. Molecules 23(10), 2684. doi: 10.3390/molecules23102684.

[15] Lagerwall, J. P. F., Schütz, C., Salajkova, M., Noh, J., Park, J. H., et al. (2014). Cellulose nanocrystal-based materials: From liquid crystal self-assembly and glass formation to multifunctional thin films. NPG Asia Materials, 6(1), 1-12. doi: 10.1038/am.2013.69.

[16] Salas, C., Nypelö, T., Rodriguez-Abreu, C., Rojas, R. (2014). Nanocellulose properties and applications in colloids and interfaces. Current Opinion in Colloid \& Interface Science, 19(5), 383-396. doi: 10.1016/j.cocis.2014.10.003.

[17] Ching, Y. C., Ali, M. E., Abdullah, L. C., Choo, K. W., Kuan, Y. C., et al. (2016). Rheological properties of cellulose nanocrystal-embedded polymer composites: A review. Cellulose, 23(2), 1011-1030. doi: 10.1007/s10570-0160868-3.

[18] Kim, J., Montero, G., Habibi, Y., Hinestroza, J. P., Genzer, J., et al. (2009). Dispersion of cellulose crystallites by nonionic surfactants in a hydrophobic polymer matrix. Polymer Engineering and Science, 49(10), 2054-2061. doi: 10.1002/pen.21417.

[19] Li, M. C., Wu, Q., Song, K., De Hoop, C. F., Lee, S., et al. (2016). Cellulose nanocrystals and polyanionic cellulose as additives in bentonite water-based drilling fluids: Rheological modeling and filtration mechanisms. Industrial \& Engineering Chemistry Research, 55(1), 133-143. doi: 10.1021/acs.iecr.5b03510.

[20] Oguzlu, H., Danumah, C., Boluk, Y. (2017). Colloidal behavior of aqueous cellulose nanocrystal suspensions. Current Opinion in Colloid \& Interface Science, 29, 46-56. doi: 10.1016/j.cocis.2017.02.002.

[21] Buffiere, J., Balogh-Michels, Z., Borrega, M., Geiger, T., Zimmermann, T., et al. (2017). The chemical-free production of nanocelluloses from microcrystalline cellulose and their use as pickering emulsion stabilizer. Carbohydrate Polymers, 178, 48-56. doi: 10.1016/j.carbpol.2017.09.028.

[22] Lappalainen, T., Lehmonen, J. (2012). Determinations of bubble size distribution of foam-fibre mixture using circular hough transform. Nordic Pulp \& Paper Research Journal, 27(5), 930-939. doi: 10.3183/NPPRJ-2012-2705-p930-939.

[23] Al-Qararah, A. M., Ekman, A., Hjelt, T., Ketoja, J., Kiiskinen, $H$., et al. (2015). A unique microstructure of the fiber networks deposited from foam-fiber suspensions. Colloids and Surfaces A: Physicochemical and Engineering Aspects, 482, 544-553. doi: 10.1016/j.colsurfa.2015.07.010. 
[24] Buron, H., Mengual, O., Meunier, G., Cayre, I., Snabre, $P$. (2004). Optical characterization of concentrated dispersions: Applications to laboratory analyses and online process monitoring and control. Polymer International, 53(9), 1205-1209. doi: 10.1002/pi.1231.

[25] Jin, H., Zhou, W., Cao, J., Stoyanov, S. D., Blijdenstein, T. $B$., et al. (2012). Super stable foams stabilized by colloidal ethyl cellulose particles. Soft Matter, 8(7), 2194-2205. doi: 10.1039/C1SM06518A.
[26] Blijdenstein, T. B. J., de Groot, P. W. N., Stoyanov, S. D. (2010). On the link between foam coarsening and surface rheology: Why hydrophobins are so different. Soft Matter. 6(8), 1799-1808. doi: 10.1039/B925648B.

[27] Hu, Z., Xu, R., Cranston, E. D., Pelton, R. H. (2016). Stable aqueous foams from cellulose nanocrystals and methyl cellulose. Biomacromolecules, 17(12), 4095-4099. doi: 10.1021/acs.biomac.6b01641. 